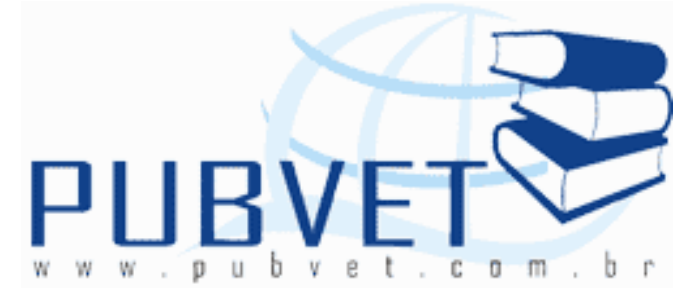

PUBVET, Publicações em Medicina Veterinária e Zootecnia.

\title{
Análise do crescimento de Brachiaria dictyoneura nos cerrados de Rondônia
}

Newton de Lucena Costa ${ }^{1}$, Valdinei Tadeu Paulino ${ }^{2}$, João Avelar Magalhães ${ }^{3}$, Claudio Ramalho Townsend ${ }^{4}$, Ricardo Gomes de Araújo Pereira ${ }^{4}$

${ }^{1}$ Eng. Agrôn., D.Sc., Embrapa Roraima, Boa Vista, RR.

${ }^{2}$ Eng. Agrôn., Ph.D., Instituto de Zootecnia, Nova Odessa, SP.

3 Med. Vet., D.Sc., Embrapa Meio Norte, Parnaíba, PI.

${ }^{4}$ Zootecnista, D.Sc., Embrapa Rondônia. Porto Velho, RO.

\section{Resumo}

Foram avaliados os efeitos da idade das plantas sobre o rendimento de forragem, vigor de rebrota e parâmetros de crescimento de Brachiaria dictyoneura. O delineamento experimental foi em blocos casualizados com três repetições. Os tratamentos constaram de cinco idades de rebrota $(14,21,28$, 35 e 42 dias após a uniformização das parcelas). O aumento da idade das plantas resultou em maiores rendimentos de forragem e índices de área foliar, contudo implicou em decréscimos significativos das taxas absolutas e relativas de crescimento e taxas de expansão foliar. A eliminação de meristemas apicais foi diretamente proporcional à idade das plantas, ocorrendo o inverso quanto ao vigor de rebrota. Considerando-se os parâmetros avaliados, o intervalo entre pastejos mais adequado, visando conciliar produção de forragem, vigor de rebrota e taxas de crescimento, situa-se entre 28 e 35 dias.

Termos para indexação: área foliar, produtividade, vigor de rebrota 


\title{
Growth analysis of Brachiaria dictyoneura in Rondônia 's savannas
}

\begin{abstract}
The effects of plant age on forage yield, regrowth vigor and growth parameters of Brachiaria dictyoneura were evaluated. The experimental design was a randomized block with three replicates. Treatments consisted of five cutting ages $(14,21,28,35$ and 42 days after the unification of the plots). The increasing age of the plants resulted in higher forage yields and leaf area index, however resulted in significant decreases in absolute and relative growth rates and leaf expansion. The elimination of apical meristems was directly proportional to the age of the plants, while the opposite occurred for regrowth vigor. Considering the parameters evaluated, the interval between grazing more appropriate, aimed at reconciling forage production, regrowth vigor and growth rates, is between 28 and 35 days.
\end{abstract}

Index terms: leaf area, yield, regrowth vigor

\section{Introdução}

Em Rondônia, as principais regiões de pecuária de corte correspondem aos municípios de Vilhena (2.372.500), Corumbiara (1.183.000), Pimenta Bueno (842.036) e Ouro Preto d'Oeste (814.908), que juntos participam com $36,89 \%$ do efetivo estadual (DIAGNÓsTICO... 2008). Nessas áreas as pastagens cultivadas representam a fonte mais econômica para alimentação dos rebanhos. No entanto, face às oscilações climáticas, a produção de forragem durante o ano apresenta flutuações estacionais, ou seja, abundância no período chuvoso (outubro a maio) e déficit no período seco (junho a setembro), o que afeta negativamente os índices de produtividade animal (COSTA et al., 1988).

A utilização de práticas de manejo adequadas é uma das alternativas para reduzir os efeitos da estacionalidade da produção de forragem. O estádio de crescimento em que a planta é colhida afeta diretamente o rendimento, composição química, capacidade de rebrota e persistência. Em geral, cortes ou 
pastejos menos frequentes fornecem maiores produções de forragem, porém, paralelamente, ocorrem decréscimos acentuados em sua composição química (COSTA; OLIVEIRA, 1994; DESCHAMPS, 1997). Logo, deve-se procurar o ponto de equilíbrio entre produção e qualidade da forragem, visando assegurar os requerimentos nutricionais dos animais e garantindo, simultaneamente, a persistência e a produtividade das pastagens.

Por outro lado, análise de crescimento revela os processos morfofisiológicos e os seus reflexos no acúmulo de massa seca da planta e do crescimento da área foliar. Esta determinação é importante porque as folhas são as principais responsáveis pela captação de energia solar e pela produção de matéria orgânica por meio da fotossíntese (MAGALHÃES, 1985; SANTOS JÚNIOR et al., 2004). Segundo Gomide et al. (2003) e Alexandrino et al. (2005), a análise crescimento é uma ferramenta bastante valiosa no entendimento das adaptações da planta sob diferentes condições de meio e manejo a que ela é submetida, definindo o seu crescimento e desenvolvimento.

Por sua vez, o capim-dictyoneura (Brachiaria dictyoneura) é uma gramínea forrageira perene, originária da África tropical, de hábito de crescimento semi-ereto a prostrado, estolonífera e rizomatosa. Essa gramínea apresenta boa produção de matéria seca com teores de proteína próximos aos $10 \%$ e tem sido indicada para cultivo em regiões de cerrados com precipitações pluviométricas superiores a $3.000 \mathrm{~mm}$ (HOYOS et al., 1997; COSTA et al., 2003, 2007).

Neste trabalho avaliaram-se os efeitos da idade de rebrota sobre a produção de forragem, vigor rebrota e parâmetros de crescimento da gramínea Brachiara dictyoneura nos cerrados de Vilhena, Rondônia.

\section{Material e Métodos}

O ensaio foi conduzido no Campo Experimental da Embrapa Rondônia, localizado no município de Vilhena (600 m de altitude, 12044' de latitude sul e 
$60^{\circ} 08^{\prime}$ de longitude oeste), durante o período de setembro de 1991 a maio de 1992.

O solo da área experimental é um Latossolo Vermelho-Amarelo, textura argilosa (fase cerrado), o qual foi cultivado por três anos consecutivos com soja (Glycine max Merril). Quando do plantio, apresentava as seguintes características químicas: $\mathrm{pH}(1: 2,5)=5,2 ; \mathrm{Al}=0,3 \mathrm{cmol} / \mathrm{dm}^{3} ; \mathrm{Ca}+\mathrm{Mg}=1,8$ $\mathrm{cmol} / \mathrm{dm}^{3} ; \mathrm{P}=3 \mathrm{mg} / \mathrm{kg}$ e $\mathrm{K}=58 \mathrm{mg} / \mathrm{kg}$.

O delineamento experimental foi em blocos casualizados com três repetições. Os tratamentos constaram de cinco idades de corte $(14,21,28,35$ e 42 dias após a uniformização das parcelas). As parcelas foram compostas por quatro linhas com 3,0 m de comprimento, espaçadas de $0,5 \mathrm{~m}$, sendo a área útil de 2,0 $\mathrm{m}^{2}$.

A adubação de estabelecimento constou da aplicação de $50 \mathrm{~kg}$ de $\mathrm{P}_{2} \mathrm{O}_{5} /$ ha, sob a forma de superfosfato triplo. As avaliações foram realizadas através de cortes mecânicos efetuados a uma altura de $15 \mathrm{~cm}$ acima do solo.

Os parâmetros avaliados foram rendimentos de matéria seca (MS), vigor de rebrota aos 21 dias após o corte, percentagem de eliminação de meristemas apicais, taxa absoluta de crescimento (TAC), taxa de crescimento da cultura (TCC), taxa de crescimento relativo (TCR), taxa de expansão foliar (TEF) e índice de área foliar (IAF). A TAC foi obtida dividindo-se o rendimento de MS, em cada idade de corte, pelo respectivo período de rebrota. A TCC foi obtida pela fórmula: TCC $=P_{2}-P_{1} / T_{2}-T_{1}$; onde $P_{2}$ e $P_{1}$ representam a produtividade de MS de duas amostragens sucessivas e, $T_{2}$ e $T_{1}$ o intervalo de tempo, em dias, transcorrido entre as amostragens. A TCR foi obtida pelo uso da expressão: $T C R=L n P_{2}-L P_{1} / T_{2}-T_{1}$; onde $L_{n P}$ e $L n P_{1}$ são os valores de logaritmos da MS de duas amostragens sucessivas e, $T_{2}$ e $T_{1}$ o intervalo de tempo, em dias, transcorrido entre as amostragens. A TEF foi calculada dividindo-se o comprimento acumulado de folhas pelo período de rebrota. 0 IAF foi determinado a partir do produto entre a massa seca de folhas verdes $\left(\mathrm{g} / \mathrm{m}^{2}\right)$ pela área foliar específica (AFE, $\mathrm{cm}^{2} /$ massa seca foliar). O vigor de 
rebrota foi avaliado através da produção de MS aos 21 dias após o corte à idade do primeiro corte.

\section{Resultados e Discussão}

A análise de regressão revelou efeito linear da idade rebrota sobre os rendimentos de MS da gramínea. Os maiores valores $(P<0,05)$ foram registrados com cortes aos $42(2.457 \mathrm{~kg} / \mathrm{ha})$ e 35 dias (2.321 kg/ha) (Figura 1). Estes valores superam em 72 e $86 \%$, respectivamente, aqueles fornecidos por cultivares de Brachiaria humidicola, submetidas a intervalos semelhantes de cortes em Latossolo Amarelo em Porto Velho, Rondônia (COSTA; PAULINO, 1999). Tendências semelhantes foram reportadas por Rodrigues et al. (2005) avaliando a influência da idade de rebrota sobre a produtividade de MS de Panicum maximum cv. Tanzânia, sob irrigação, nas condições edafoclimáticas dos tabuleiros costeiros do Piauí.

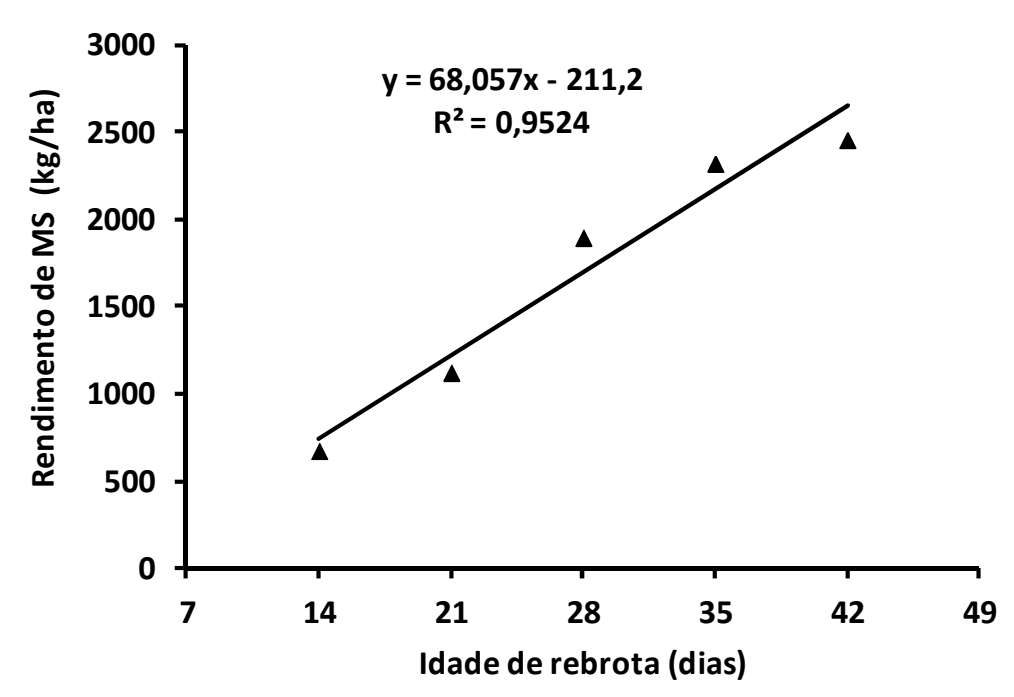

Figura 1. Rendimento de matéria seca de Brachiaria dictyoneura, em função da idade de rebrota.

A eliminação de meristemas apicais ocorreu apenas aos $42(8,7 \%)$ e 35 dias de rebrota $(5,1 \%)$. Costa (2004) constatou que a remoção de meristemas apicais de $B$. brizantha $\mathrm{cv}$. Xaraés foi diretamente proporcional à idade de 
rebrota (23,2; 28,4 e 38,1\%, respectivamente, aos 35, 42 e 49 dias). O vigor de rebrota foi afetado pela idade das plantas e negativamente correlacionado com a percentagem de eliminação de meristemas apicais $(r=-0,703$; $p=0,048)$. O efeito da idade da planta sobre o vigor de rebrota ajustou-se ao modelo quadrático de regressão, sendo o máximo valor estimado aos 31,9 dias (1.655 kg/ha) (Figura 2). A preservação dos meristemas apicais favorece a formação de novas folhas mais rapidamente e, por conseguinte, a rebrota das plantas será acelerada (LEMAIRE, 1991; CECATO et al., 2000). Costa (2004) reportou maior vigor de rebrota em pastagens de $B$. brizantha $\mathrm{cv}$. Marandu submetidas a períodos de descanso de 35 dias $(1.457 \mathrm{~kg} / \mathrm{ha} / 21$ dias), comparativamente a $28(1.172 \mathrm{~kg} / \mathrm{ha} / 21$ dias $)$ ou 42 dias $(1.217 \mathrm{~kg} / \mathrm{ha} / 21$ dias).

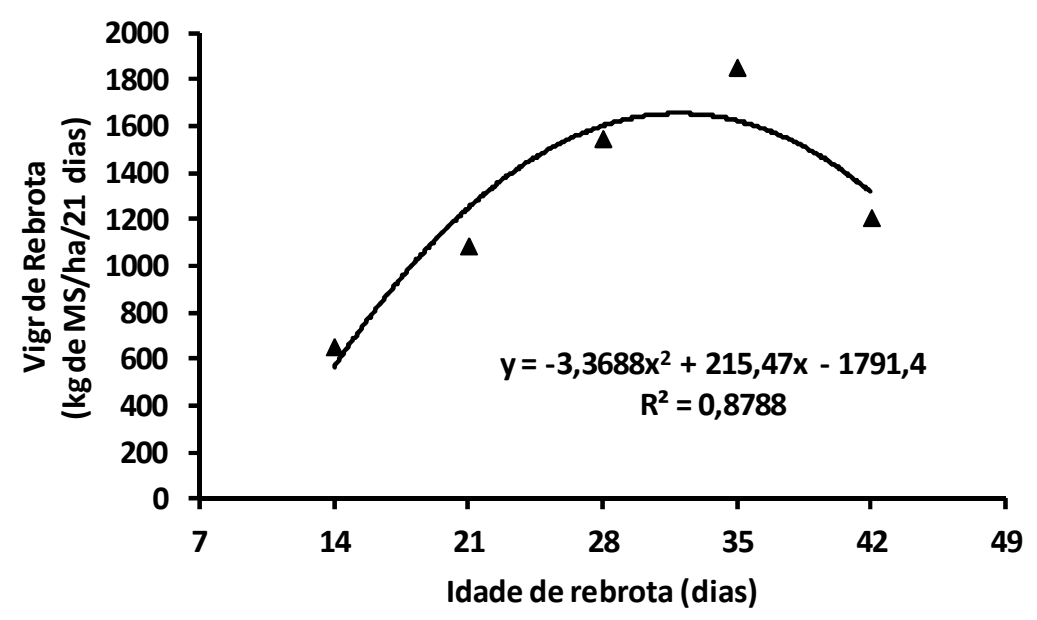

Figura 2. Vigor de rebrota de Brachiaria dictyoneura, em função da idade de rebrota.

Os efeitos da idade de rebrota sobre a TAC e a TCC foram ajustados ao modelo quadrático e os máximos valores estimados aos $31,9(65,8 \mathrm{~kg} / \mathrm{ha} / \mathrm{dia})$ e 28,6 dias (94,9 kg/ha/dia) (Figuras 3 e 4), enquanto que para a TCR a relação foi exponencial (Figura 5). Para todas as idades de rebrota, as TAC fornecidas pela gramínea foram superiores àquelas relatadas por Duarte et al. (1994) para Brachiaria brizantha e B. dictyoneura e Berroterán (1989) para Andropogon gayanus, porém inferiores às reportadas por Gomide et al. (1997) 
para B. decumbens. Resultados semelhantes foram obtidos por Costa (2004) com $B$. humidicola, que estimou valores máximos para TCC e TCR no período entre 28 e 35 dias de rebrota. As altas taxas de crescimento, durante os períodos iniciais de rebrota, representam um mecanismo de adaptação da gramínea, pois ao reduzir o tempo para que ocorra a máxima interceptação da radiação solar incidente, promove melhor utilização da água devido ao sombreamento mais rápido do solo, o que favorece sua competitividade intraespecífica (LEMAIRE, 2001). Para Parsons \& Chapman (2000) e Lemaire \& Agnusdei (2000), o período mais adequado para a utilização de uma pastagem seria aquele em que as TAC e TCC são equivalentes, de modo a maximizar o acúmulo líquido de forragem e evitar as perdas por senescência que ocorrem a partir do momento em que as TAC são decrescentes e as variações na TCC são pequenas. Considerando-se esta premissa, no presente trabalho, o período entre 28 e 35 de rebrota seria o mais recomendado para o pastejo, pois concilia a otimização entre a TAC e a TCC da gramínea.

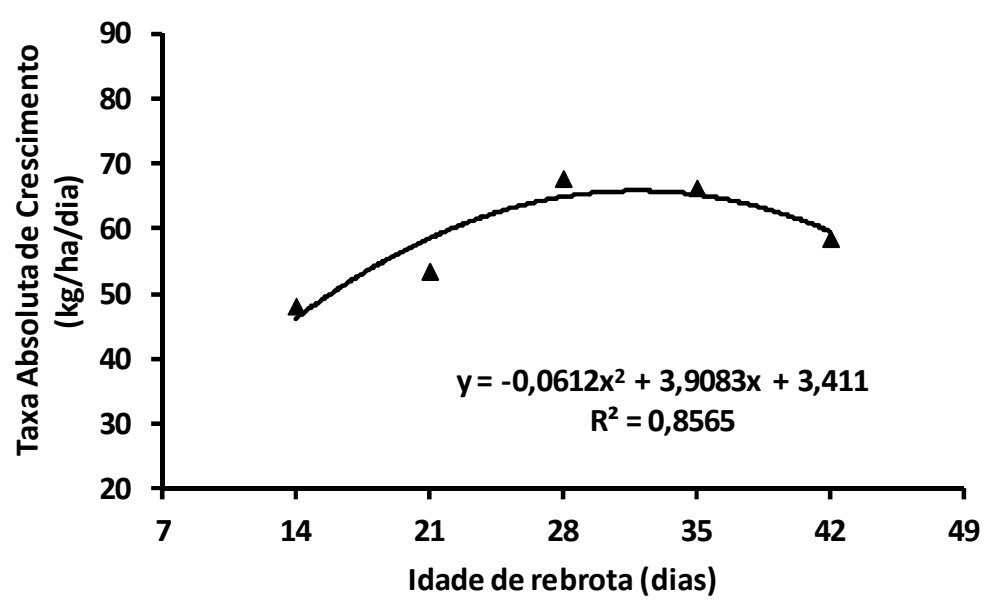

Figura 3. Taxa absoluta de crescimento de Brachiaria dictyoneura, em função da idade de rebrota. 


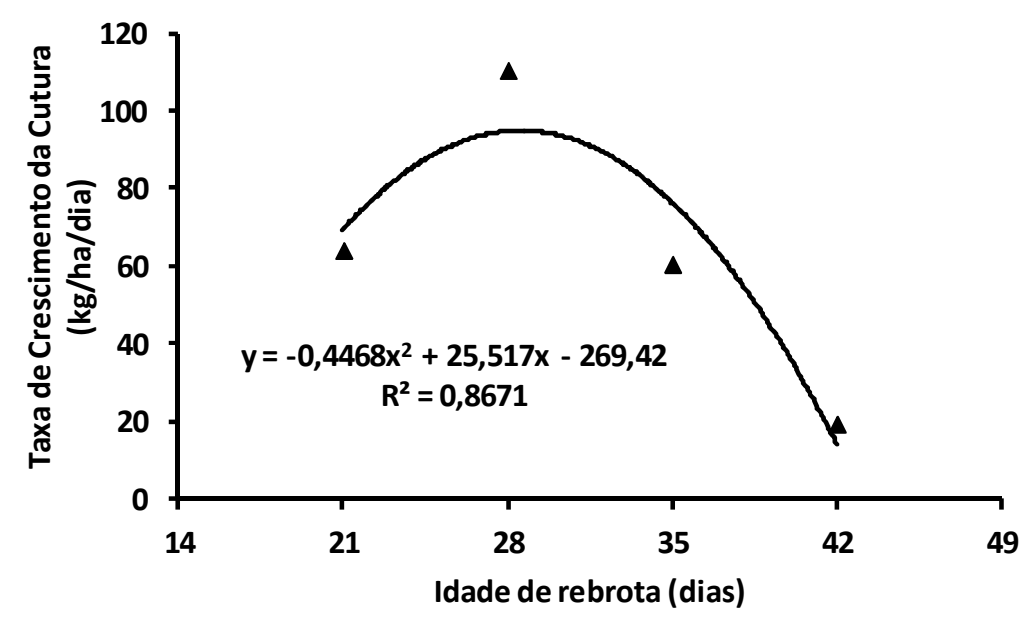

Figura 4. Taxa de crescimento da cultura de Brachiaria dictyoneura, em função da idade de rebrota.

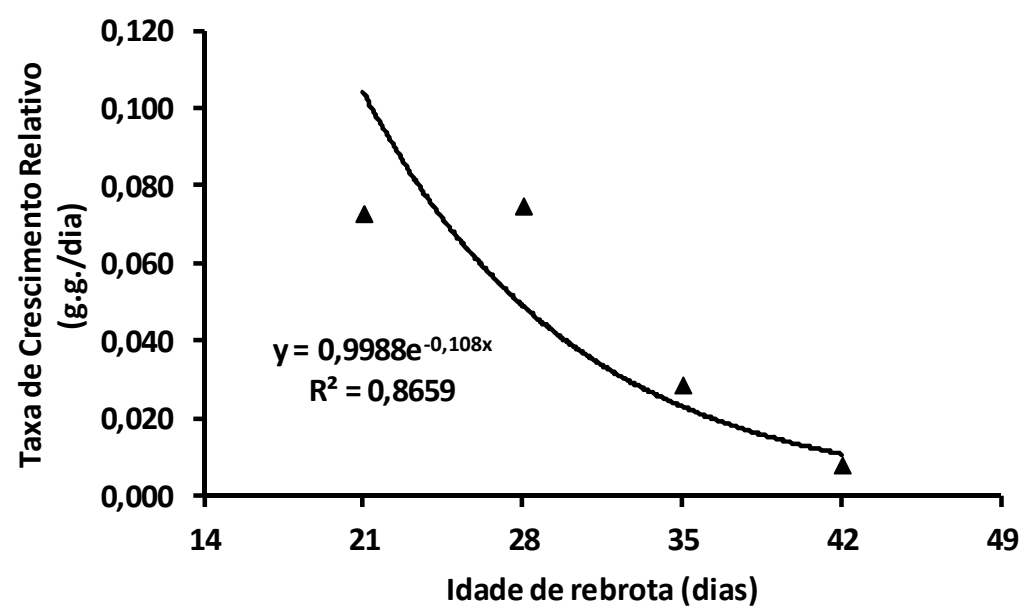

Figura 5. Taxa de crescimento relativo de Brachiaria dictyoneura, em função da idade de rebrota.

A TEF foi inversamente proporcional à idade de rebrota, ocorrendo o oposto quanto ao IAF (Figuras 6 e 7). As TEF obtidas neste trabalho, independentemente dos períodos de rebrota, foram superiores às reportadas por Corsi et al. (1994) para B. brizantha, B. humidicola e B. decumbens e por Gomide et al. (1997) para B. decumbens. As TEF explicaram em 92,2\% os incrementos verificados nos rendimentos de MS da gramínea, em função da idade de rebrota. Resultados semelhantes foram relatados por Ludlow \& $\mathrm{Ng}$ 
(1977) para P. maximum var. trichoglume. Os IAF registrados foram superiores aos verificados por Berroterán (1989) para A. gayanus e Costa (2004) para $B$. brizantha cv. Xaraés, ambas gramíneas submetidas a diferentes frequências de corte. Gramíneas com maior habilidade competitiva são aquelas que desenvolvem uma arquitetura mais eficiente na interceptação de luz, através da rápida expansão de área foliar e colonização da camada superior do dossel, em decorrência do alongamento da bainha e entrenós do colmo (LEMAIRE, 2001).

Os maiores IAF foram obtidos com cortes aos $42(3,07)$ e 35 dias $(2,86)$, os quais foram superiores aos verificados por Berroterán (1989) para $A$. gayanus e Costa et al. (2007) para B. humidicola cv. Tupi, ambas gramíneas submetidas a diferentes frequências de corte. No entanto foram inferiores aos observados Santos Júnior et al. (2005) aos 40 dias, após adubar $P$. maximum cv. Tanzânia com doses anuais de $300 \mathrm{~kg}$ de nitrogênio. A regressão linear múltipla para o rendimento de MS, em função do IAF e TEF revelou significância apenas para o IAF: $y=698+675,9 *$ IAF $-167,6^{\text {NS }}$ TEF $\left(r^{2}=\right.$ 0,9751 ), evidenciando que esta característica estrutural é a que mais contribui para o rendimento final de forragem.

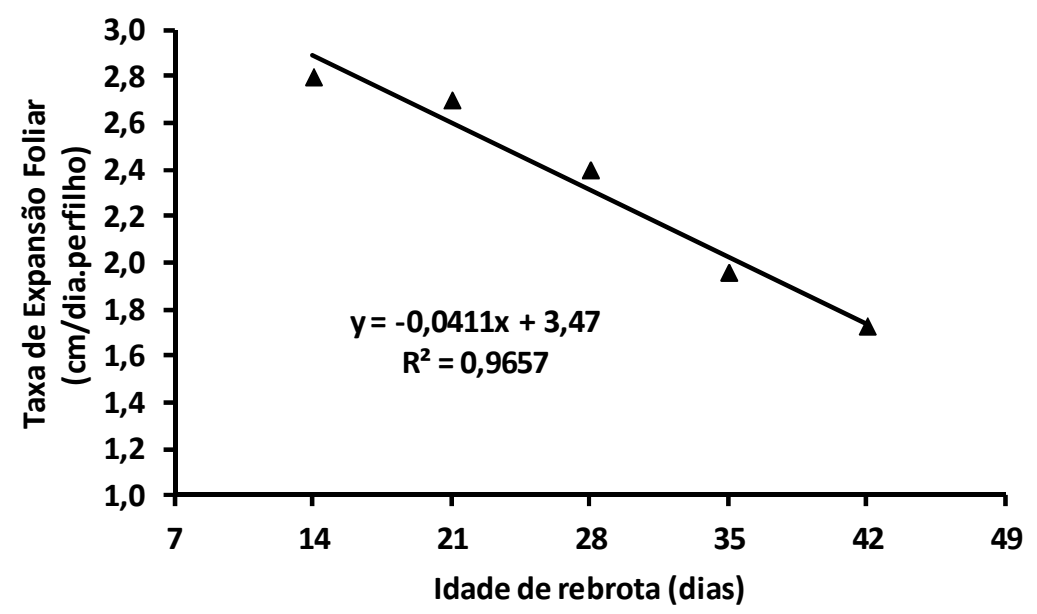

Figura 6. Taxa de expansão foliar de Brachiaria dictyoneura, em função da idade de rebrota. 


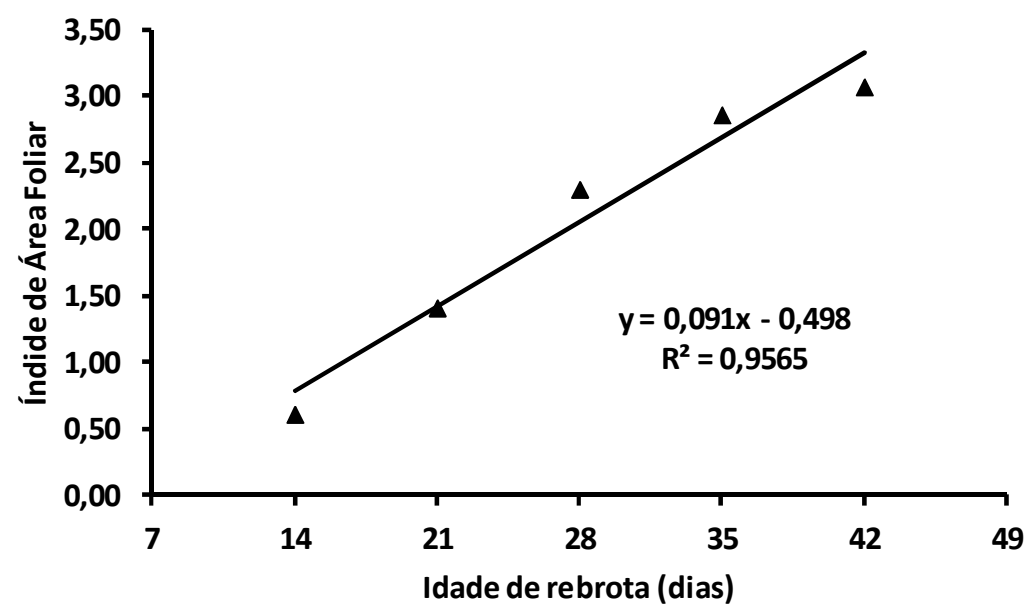

Figura 7. Índice de área foliar de Brachiaria dictyoneura, em função da idade de rebrota.

\section{Conclusões}

O aumento da idade de rebrota resulta em maiores rendimentos de forragem e índices de área foliar, contudo reduz as taxas absoluta e relativa de crescimento e a expansão foliar.

A eliminação de meristemas apicais é diretamente proporcional à idade das plantas, ocorrendo o inverso quanto ao vigor de rebrota.

Considerando-se os parâmetros avaliados, o intervalo entre pastejos mais adequado, visando conciliar produção de forragem, vigor de rebrota e taxas de crescimento, situa-se entre 28 e 35 dias.

\section{Referências Bibliográficas}

ALEXANDRINO, E.; GOMIDE, J.A.; GOMIDE, C.A.M. Crescimento do dossel de Panicum maximum cv Mombaça. Revista Brasileira de Zootecnia, v.34, n.6, p.2164-2173, 2005.

BERROTERÁN, J.L. Respuesta de Andropogon gayanus y Digitaria swazilandensis a la fertilización en los Llanos Centrales de Venezuela. Pasturas Tropicales, v.11, n.2, p.2-7, 1989.

CECATO, U.; MACHADO, E.N.; MARTINS, E.; PEREIRA, L.A.; BARBOSA, M.A.A.; SANTOS, G.T. Avaliação da produção e de algumas características da rebrota de cultivares e acessos de Panicum maximum Jacq. sob duas alturas de corte. Revista Brasileira de Zootecnia, v.29, n.3, p.660-668, 2000.

CORSI, M.; BALSALOBRE, M.A.; SANTOS, P.M.; SILVA, S.C. da. Bases para o estabelecimento do manejo de pastagens de braquiária. In: SIMPÓSIO SOBRE MANEJO DA PASTAGEM, 11., 1994. Piracicaba. Anais... Piracicaba: FEALQ, 1994, p.249-266. 
COSTA, N. de L. Formação, manejo e recuperação de pastagens em Rondônia. Porto Velho: Embrapa Rondônia, 2004. 215p.

COSTA, N. de L.; GONÇALVES, C.A.; OLIVEIRA, M.A.S.; OLIVEIRA, J.R.C. Rendimento de gramíneas forrageiras em Ariquemes-RO. Porto Velho: EMBRAPA-UEPAE Porto Velho, 1988. 4p. (Comunicado Técnico, 63).

COSTA, N. de L.; MAGALHÃES, J.A.; PEREIRA, R.G.A.; TOWNSEND, C.R.; OLIVEIRA, J.R.C. Considerações sobre o manejo de pastagens na Amazônia Ocidental. Revista do Conselho Federal de Medicina Veterinária, v.13, p.37-55, 2007.

COSTA, N. de L.; OLIVEIRA, J.R.C. Evaluación agronómica de accesiones de Panicum maximum en Rondônia. Pasturas Tropicales, v.16, n.2, p.44-46, 1994.

COSTA, N. de L.; PAULINO, V.T. Desempenho agronômico de genótipos de Brachiaria humidicola em diferentes idades de corte. Pasturas Tropicales, v. 21, n.2, p. 65-68, 1999.

COSTA, N. de L.; PAULINO, V.T.; TOWNSEND, C.R.; MAGALHÃES, J.A.; OLIVEIRA, J.R.C. Desempenho agronômico de genótipos de Brachiaria brizantha em diferentes idades de corte em Porto Velho, Rondônia, Brasil. Revista Electrónica de Veterinaria, v.8, p.1-6, 2007.

COSTA, N. de L.; TOWNSEND, C.R.; MAGALHÃES, J.A.; OLIVEIRA, J.R.C. Formação e manejo de pastagens de Brachiaria dictyoneura em Rondônia. Porto Velho: Embrapa Rondônia, 2003. 4p. (Recomendações Técnicas, 66).

DIAGNÓSTICO da pecuária em Rondônia. Disponível no site: http://www.klimanaturali.org/2008/12/diagnostico-da-pecuaria-em-rondonia.html

DESCHAMPS, F.C. Perfil fenológico de três ecotipos de capim-elefante (Pennisetum purpureum Schum.). In: REUNIÃO ANUAL DA SOCIEDADE BRASILEIRA DE ZOOTECNIA, 34., 1997, Juiz de Fora. Anais... Juiz de Fora: SBZ, 1997, p.62-64.

DUARTE, J.M.; PEZO, D.A.; ARZE, J. Crecimiento de tres gramíneas forrajeras establecidas en cultivo intercalado con maíz (Zea mays L.) o vigna (Vigna unguiculata (L.)Walp.). Pasturas Tropicales, v.16, n.1, p.8-14, 1994.

GOMIDE, C.A.M.; GOMIDE, J.A.; QUEIROZ, D.S.; PACIULLO, D.S.C. Fluxo de tecidos em Brachiaria decumbens. In: REUNIÃO ANUAL DA SOCIEDADE BRASILEIRA DE ZOOTECNIA, 34., 1997, Juiz de Fora. Anais... Juiz de Fora: SBZ, 1997, p.117-119.

GOMIDE, C.A.M.; GOMIDE, J.A.; ALEXANDRINO E. Índices morfogênicos e de crescimento durante o estabelecimento e a rebrotação do capim-Mombaça (Panicum maximum Jacques). Revista Brasileira de Zootecnia, v.32, n.4, p.795-803, 2003.

HOYOS, P.; MOLINA, D.L.; VERA, R.R. Efecto de la fertilización en el rendimiento de semilla de Brachiaria dictyoneura cv. Llanero en la altillanura Colombiana. Pasturas Tropicales, v.19, n.2, p.35-39, 1997.

LEMAIRE, G. Physiologie des graminées fourragéres: croissance. Technology Agriculture, n.220, p.3-18, 1991.

LEMAIRE, G. Ecophysiological of grasslands: Dynamics aspects of forage plant population in grazed swards. In: INTERNATIONAL GRASSLAND CONGRESS, 19., 2001, São Paulo, Proceedings... São Paulo: ESALQ, 2001, p.29-37.

LEMAIRE, G.; AGNUSDEI, M. Leaf tissue turnover and efficiency of herbage utilization. In: LEMAIRE, G.; HODGSON, J.; MORAES, A.; CARVALHO, P.C.F.; NABINGER, C. (Eds.). Grassland ecophysiology and grazing ecology. London: $C A B$ International, 2000. p.265288. 
LUDLOW, M.M.; NG, T.T. Leaf elongation rate in Panicum maximum var. trichoglume following removal of water stress. Australian Journal of Plant Physiology, v.4, n.2, p.263-272, 1977.

MAGALHÃES, A.C.N. Análise quantitativa do crescimento. In: FERRI, M.G. (Coord.). Fisiologia vegetal. 2.ed. rev. atual. São Paulo: Ed. Pedagógica e Universitária, 1985. v.1, cap.8, p.33350 .

PARSONS, A.J.; CHAPMAN, D.F. The principles of pasture growth and utilization. In: HOPKINS, A. (Ed.). Grass, its production and utilization. London: Blackwell Science, p.31-89, 2000.

RODRIGUES, B.H.N.; MAGALHÃES, J.A.; CAVALCANTE, R.F.; BARROS, W.S. de. Efeito da frequência de corte sobre o rendimento forrageiro do capim-Tanzânia irrigado, em ParnaíbaPiauí. In: CONGRESSO NACIONAL DE IRRIGAÇÃO E DRENAGEM, 15., 2005, Teresina. Anais... Teresina: ABID/EMBRAPA MEIO-NORTE, 2005.

SANTOS JÚNIOR, J.D.G.; MONTEIRO, F.A.; LAVRES JÚNIOR, J. Análise de crescimento de capim-marandu submetido a doses de nitrogênio. Revista Brasileira de Zootecnia, v.33, n.6, supl.2, p.23-26, 2004.

SANTOS JÚNIOR, J.D.G.; MONTEIRO, F.A.; MACEDO, M.C.M.; EUCLIDES, V.P.B. Componentes morfológicos do capim-Tanzânia cultivado em quatro condições de fertilidade do solo na região dos cerrados. Boletim da Indústria Animal, v.62, n.2, p.91-99, 2005. 